\title{
Using Supplemental Instruction to Bridge the Transition from Secondary to Tertiary Education
}

\author{
Joakim Malm ${ }^{*}$, Lise-Lotte Mörner ${ }^{1}$, Leif Bryngfors ${ }^{2}$, Gunilla Edman ${ }^{3} \&$ \\ Leif Gustafsson ${ }^{4}$
}

${ }^{1}$ Center for Supplemental Instruction, Faculty of Engineering, Lund University

PO Box 118, S-22100 Lund, Sweden

Tel: +46-46-2223715Ｅ-mail: Lise-Lotte.Morner@kansli.lth.se

${ }^{2}$ Center for Supplemental Instruction, Faculty of Engineering, Lund University

PO Box 118, S-22100 Lund, Sweden

Tel: +46-46-2227180 E-mail: Leif.Bryngfors@kansli.lth.se

${ }^{3}$ Spyken Upper Secondary School, Lunds kommun

PO Box 2003, S-22002 Lund, Sweden

Tel: +46-46-357858Ｅ-mail: Gunilla.Edman@utb.lund.se

${ }^{4}$ Spyken Upper Secondary School, Lunds kommun

PO Box 2003, S-22002 Lund, Sweden

Tel: +46-46-357858Ｅ-mail: Leif.Gustafsson@utb.lund.se

Corresponding author: Joakim Malm, Center for Supplemental Instruction, Faculty of Engineering, Lund University; PO Box 118, S-22100 Lund, Sweden; Tel: +46-46-2227571 E-mail: Joakim.Malm@kansli.lth.se

Received: May 27, 2012 Accepted: June 21, 2012 Published: August 12, 2012 doi:10.5296/ije.v4i3.1826 URL: http://dx.doi.org/10.5296/ije.v4i3.1826 


\begin{abstract}
Supplemental Instruction (SI) is today a well known academic assistance program, providing help for students in "difficult" courses at colleges and universities. Little attention has been paid however to the possibility of also implementing the SI program in upper secondary school. In this study we present qualitative results from such an SI program in a Swedish setting. Here, students from the faculty of engineering at Lund University, act as SI leaders at eleven upper secondary schools in the local region, in subjects such as math, physics and chemistry. The main conclusion is that the SI methodology also seems to work in an upper secondary school environment. The students who attend SI regularly appear to obtain new study strategies to increase their understanding of the subject, besides improving on general skills such as teamwork, communicating on a subject, and making presentations in front of others. There are several advantages for the schools and university involved. For example they gain a formal and an informal link, which can prove useful in many circumstances when an exchange of information is needed, and both can use SI as a means to boost recruitment. For the upper secondary school, the students can get an alternative view on subjects, which hopefully stimulates interest and understanding. The students also get a more mature role model to turn to. For the university an additional advantage is that a more informal view of what it is like to study at university can be provided to upper secondary school students.
\end{abstract}

Keywords: supplemental instruction, upper secondary school, science, engineering 


\section{Introduction}

Supplemental Instruction (SI) is used at many universities around the world to improve results in difficult courses, and to develop the students' study strategies (Martin 2008; Hurley, Jacobs and Gilbert 2006). SI is based on collaborative learning with an older student as facilitator, and has repeatedly been shown to give positive results for all kinds of courses in different settings (Blanc et al., 1983; Burmeister, Kenney, and Nice, 1996; Congos and Schoeps, 1993; Hensen and Shelley, 2003; Malm, Bryngfors and Mörner, 2011; Ogden, Thompson, Russell, and Simons, 2003; Packham and Miller, 2000; Power and Dunphy, 2010; Ramirez, 1997; Rye, Wallace, and Bidgood, 1993; Sawyer, Sylvestre, Girard, and Snow, 1996; Webster and Hooper, 1998; Wright, Wright, and Lamb, 2002). It should be of interest to see whether SI also works at a lower educational level than tertiary education. The advantages can however be more than just increasing examination results and improving the students study strategies, for instance there is the creation of a link between secondary and tertiary education, using university students as SI leaders in upper secondary school. In this way, upper secondary school students gain a personal view of tertiary education and what is required for study at this level. The upper secondary schools can use the collaboration with the university in their recruitment information. The university benefits in a similar way by creating interest in higher level studies, within the upper secondary school, by the informal meeting between a university student and the school students.

At the faculty of engineering at Lund University, Sweden, such a cooperation was created in 2007 and today includes eleven upper secondary schools in the local region. There are several potential advantages to the cooperation, besides those mentioned above. For the faculty of engineering they include

- Creating an interest in science and technology in upper secondary school

- Targeting upper secondary schools in areas where people with tertiary education are uncommon

- Academic leadership experience for university students

For the upper secondary school the additional advantages include

- Creating an extra learning opportunity in difficult courses like math, physics and chemistry

- Developing study strategies for students, such as increased abilities for collaboration, discussion, viewing fellow students as resources in a learning perspective, and developing the students responsibility for their own learning

- Giving students an insight into what it is like to study at university through the informal meetings with the university student

The objective of this article is partly to describe how the SI program works in an upper secondary school environment, since this is a new implementation. Furthermore, it is to qualitatively evaluate the SI program, to get an insight into potential positive effects as well as challenges that may be experienced. Since the SI program is set up in a Swedish education system the results are obviously not directly transferable to a different education system. 
However, the results can provide an indication of the potential of the SI methodology in an upper secondary school environment, and its function as a link between secondary and tertiary education.

\section{Description of the SI program in upper secondary schools}

There are in total, eleven schools in the local region participating in the SI program. Normally there are two SI leaders working at each school, in math, physics or chemistry. The intention is that the SI leaders should be able to alternate between the subjects dependent on the wishes of the students. The SI meetings are usually only for a selected class (studying science or technology) at the school. Participation is often mandatory initially so that everyone is able to get firsthand experience of SI. Thereafter attending SI sessions becomes optional.

Before each new academic year a contract between the school and the faculty of engineering is drawn up and signed, specifying what each party commits to within the cooperation. If these commitments are not fulfilled, either party has the right to immediately end the cooperation. The contract has been shown to be necessary in clarifying roles and responsibilities in order to optimize the function of the SI program. Before each academic year SI leaders are selected. Potential SI leaders are recommended by current SI leaders working at the faculty of engineering, based on a good attendance record at SI, and good social and leadership skills. The recommended university students can thus apply for the position of SI leader at an upper secondary school. Based on the application, study results and a subsequent interview, approximately 20 SI leaders are selected for the eleven schools. The SI leaders are requested to get in contact with the upper secondary school well in advance of the new academic year, so that the SI sessions can be scheduled, and contact with the responsible teachers can be established. The SI leaders receive a two day training just before they start their work. Usually they have one SI session of 1-1.5 hours duration per week, throughout the whole academic year. The total work time per week for each SI leader is about five hours, including preparation, contact with the teacher, short report submission from each meeting, supervision and travel to/from the school. The SI leaders are paid for their work.

A typical SI session originates from material that the upper secondary school students have perceived as difficult during the preceding week, in math, physics or chemistry. It can for instance concern concepts, formulas or problems. Alternatively, if the students do not have suggestions of material to cover, the SI leader will have prepared some material to work with. The work is then done in collaboration. The form of collaboration (for instance jigsaw, work in small groups, etc.) is chosen by the SI leader dependent on the situation and material. The SI session is usually concluded by the students summarizing their results on the white board.

During the academic year, one SI session is located at the faculty of engineering. Besides the actual SI session there is usually a tour of campus, a glimpse of how university education is carried out and perhaps a short lecture given by a professor on some interesting topic. The students are also invited to a coffee break, so that they can ask their SI leader questions on what it is like to study at university and about student life in general.

Supervision meetings (about one hour in duration) are arranged every other week, so the SI 
leader can obtain help to develop and share ideas on how to handle tough situations that may arise. The meetings focus partly on the SI leaders' most recent experiences and are covered in small group discussions. Special situations that some SI leaders encountered are brought up and possible solutions are discussed. Furthermore, there is a focus on how to create good discussions, collaboration and group dynamics.

The contact between the upper secondary schools and the faculty of engineering is reinforced by yearly visits to each school by SI staff from the faculty of engineering, so that the SI cooperation can be discussed. Furthermore, a yearly "teacher day" at the faculty of engineering is arranged so that all schools can exchange experiences.

Besides the SI program described above, there are three schools that run an SI program with older students guiding younger students - two upper secondary schools (ages 16-19) and one intermediate school (ages 13-15). The faculty of engineering here provides the SI leader training. These three schools express a high degree of satisfaction with the SI method. However, no published evaluation material exists.

\section{Evaluation methods}

In the evaluation we have focused on several areas to obtain an indication of how the SI program is working. These areas are

- Attendance at SI sessions

- Reasons why students participate in SI sessions

- The views of students, SI leaders, and teachers, on the SI sessions

- The views of students, SI leaders, and teachers, on students' development in math/physics/chemistry, due to SI

- The view of students, SI leaders, and teachers, on students' development in study strategies and general skills, due to SI

- The SI leaders' view on their leadership development

- The teachers' view on the SI program in general

To receive information regarding these areas, weekly reports from SI leaders (containing attendance records) together with a number of questionnaires, were used. The data was collected during the academic year 2010/11 (general surveys) and 2011/12 (special survey).

The survey questions put to students, SI leaders and teachers, are provided in table 1-3. The questionnaire to the students was limited to students who attended more than a third of available SI sessions. In total $44 \%$ (120 of 297) of these students answered the survey. 16 of 20 SI leaders $(80 \%)$ answered their questionnaire, and eight teachers completed their survey.

In order to see which skills the students develop through SI, a special questionnaire was handed out to two classes - one receiving SI and one not receiving SI - at one school. The questions on this special survey are supplied in table 4 . 


\section{Macrothink}

Table 1. Questions on survey of SI attendees at upper secondary schools

\section{Open-ended questions}

What do you think is the best aspect of the SI sessions?

What do you think primarily needs to be improved in the SI sessions?

How do SI sessions differ from ordinary lessons?

Have the SI sessions changed the way you study? How?

Questions within different areas with five response alternatives (Never true, Sometimes true, True about half of the time, Frequently true, Always true)

General opinion of SI sessions

Overall I'm satisfied with the SI sessions

\section{Reason for attending SI sessions}

To pass the course

To get a good grade on the course

To understand the subject better

Because it is fun to study and discuss course content with class mates

Because I have noted that it is an efficient way of studying

Opinion on how SI has developed the student in the course/subject

The SI sessions have given me a deeper understanding of the course content

The SI sessions have increased my interest in the subject

By attending SI sessions I have improved my results in the course

The SI sessions have been an effective support to help me proceed in the course

Opinion on how the student perceives the development regarding study strategies/general skills

The SI sessions have developed my way of studying. This will also be useful in other courses.

The SI sessions have developed my abilities in problem solving

The SI sessions have developed my ability in teamwork and collaboration in a group

The SI sessions have developed my ability to critically review material/questions/solutions in the course, by group discussions

The SI sessions have developed my ability to present problems/solutions on the subject in front of others

I have obtained better self confidence in my studies by attending SI sessions 


\section{Ml Macrothink}

International Journal of Education

ISSN 1948-5476

2012, Vol. 4, No. 3

Table 2. Questions on survey of upper secondary school teachers

\section{Open-ended questions}

Comment on how useful it has been for you to have SI sessions to complement your teaching

What comments have you heard from your students regarding the SI sessions?

What do you see as the main influence that the SI sessions have had on your students?

Have the SI sessions had any influence on the test results of your students (who attended SI sessions)?

What is your impression of the contact between you and the SI group at the faculty of engineering?

Table 3. Questions on survey of SI leaders

\section{Open-ended questions}

What do you think has been most rewarding for you in your work as an SI leader?

What do you think has been least rewarding for you in your work as an SI leader?

In what ways have your SI sessions affected your students?

List and explain three things that you have improved upon by being an SI leader

Questions within different areas with five response alternatives (Never true, Sometimes true, True about half the time, Frequently true, Always true)

General opinion of SI session

Overall I am satisfied with my SI sessions

Opinion of how the SI leader perceives that the students have developed/been trained regarding study strategies/general skills

I normally share my experiences of what it is like to study at university and efficient ways of studying

The SI sessions have developed the students' abilities in problem solving

The SI sessions have developed the students' abilities in team work and collaboration in groups

The SI sessions have developed the students' abilities to present problems/solutions in front of others

The SI sessions have developed the students' abilities to critically review material/questions/solutions in the course, by group discussions

The SI leader's opinion of personal development due to their work as an SI leader

By being an SI leader I have improved my self confidence

By working as an SI leader I have improved my ability to talk in front of others

I have improved my ability to organize the work for a group

I feel more secure in being a leader of a group

I feel more secure in leading a discussion

I have improved my ability to meet and inspire different individuals

I have developed my ability to enthuse a group of individuals to undertake a task

I have become good at getting the students to help each other with the course 
Table 4. Questions on special survey of students in two classes (one with and one without SI) at one upper secondary school

Questions within different areas, with five response alternatives (Never true, Sometimes true, True about half the time, Frequently true, Always true)

I learn mathematics best by

- working on my own

- working together with a classmate

- explaining to a classmate

- listening to the teacher explaining to the class

- discussing a problem together with the whole class

- working with problems in small groups

- watching classmates solving problems on the whiteboard in front of the class

- solving a problem on the whiteboard in front of the class

\section{Results}

During the academic year 2010/11 there was 20 SI leaders working at eleven upper secondary schools. On average about 20 SI sessions were conducted per SI leader during the year. At each SI session there were about eight students attending on average. If we consider the percentage of students (that at least attended one SI session) with low, average and high attendance at available SI sessions, we get the following distribution:

\begin{tabular}{lccc}
\hline Attendance - percentage of available SI sessions & $\begin{array}{c}\text { Low } \\
(0-33 \%)\end{array}$ & $\begin{array}{c}\text { Average } \\
(33-67 \%)\end{array}$ & $\begin{array}{c}\text { High } \\
(67-100 \%)\end{array}$ \\
\hline Percentage of students (\%) & $\mathbf{3 9}$ & $\mathbf{3 2}$ & $\mathbf{2 9}$ \\
\hline
\end{tabular}

Thus we see it is rather evenly distributed, despite almost $40 \%$ of students having low attendance at SI sessions. The majority of these stopped attending SI once it became optional. No full-scale analysis of reasons for not attending SI sessions was made. One short questionnaire by one teacher at one school showed that there were several reasons for not attending, from not finding the SI method appealing, to poor scheduling of SI sessions and conflicting activities. However, it is positive to find out that the majority of the students attended SI sessions at an average or high rate. These were also the students who had the opportunity to answer the questionnaire.

How then did the SI sessions work in the upper secondary schools? In the answers to the questionnaire from the attendees, $76 \%$ were either satisfied or frequently satisfied with the SI sessions. Only $8 \%$ were not satisfied or only sometimes satisfied with the SI sessions. All SI leaders were satisfied or frequently satisfied with how their SI sessions turned out. Except one SI leader who was only partially satisfied. What then is the opinion of the teachers on the SI sessions? Most have received a positive image from their students who attended the SI sessions regularly. Some examples of answers from teachers on the question "What comments have you heard from your students regarding the SI sessions?" are as follows: 
"They are really satisfied with the SI sessions. They have been both pleasant and rewarding."

"Only a part of the class attended the SI sessions regularly and these students have been positive"

"The students have a rather varied view on the SI sessions. Some say that they have so much to do that they will not attend something that does not immediately reward them with a higher grade. Other students have been positive to the meetings and believe it helps them with their other studies"

The last comment shows one of the difficulties with "selling" the SI method to all students, since many cannot see the immediate benefits of attending the sessions.

What then are the main reasons for attending sessions according to the students who participated in SI sessions on an average or high attendance basis? Five alternative reasons were suggested on the questionnaire. The answers to these are given in table 5. Passing the course is obviously not a main reason for attending SI sessions. The reasons that the majority felt were frequently true, or true, were "to understand the subject better" and "because it is fun to study and discuss the course content with fellow students".

Table 5. Students' reasons for attending SI sessions. Below the percentage (\%) of students is given for each alternative answer

\begin{tabular}{lccccc}
\hline & 0 & & \\
& 43 & 20 & 19 & 8 & 10 \\
\hline To pass the course & 19 & 18 & 18 & 28 & 17 \\
To get a good grade on the course & 9 & 16 & 20 & 29 & 26 \\
To understand the subject better & 9 & 13 & 21 & 36 & 20 \\
Because it is fun to study and discuss course content with class mates & 15 & 24 & 24 & 25 & 12 \\
Because I noted that it is an efficient way of studying & & & & \\
\hline
\end{tabular}

Do average and frequent SI session participants consider that their attendance developed them in the course/subject? Answers on the corresponding questions in the survey are given in table 6. In general they are rather cautious in their opinions. Especially regarding whether attending SI sessions has improved their results in the course. Only $19 \%$ consider this to be true or likely true. Moreover for the teachers it is not evident that attending SI sessions leads to better results in the course. On the question "Have the SI sessions had any influence on the test results of your students (that attended SI sessions)?" the majority couldn't clearly say. A couple of exceptions exist however: 
"I can see a relation between results on written tests and their general performance, between the students attending SI and those not attending, with the advantage for the attendees."

"Regarding the four students that attended SI regularly I can without any doubt answer yes for two of them. The other two have improved their self esteem and are calmer in test situations compared to before (these two students always performed well on tests.)."

The most considerable influence that the SI sessions had on students attending SI regularly was an improved understanding of the course content. Almost half of the respondents consider this to be true or frequently true. That the SI attendees actually get a better understanding of course content is also evident from the comments on the question, "What do you think is the best aspect of the SI sessions?". Some examples:

"That you review possible solutions to problems together and thereby get a better understanding"

"That you can discuss in a group and that it is easier to learn"

"We focus on material we find difficult and get a better understanding of the subject we cover"

Table 6. Answers to questions put to attendees about the influence of SI sessions on the course/subject. Below the percentage $(\%)$ of students is given for each alternative answer

\begin{tabular}{|c|c|c|c|c|c|}
\hline & 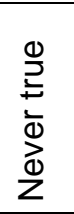 & 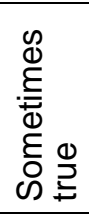 & 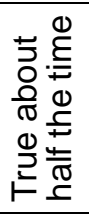 & 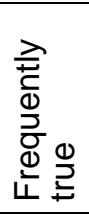 & 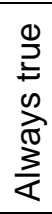 \\
\hline $\begin{array}{l}\text { The SI sessions have given me a deeper understanding of the course } \\
\text { content }\end{array}$ & 7 & 23 & 23 & 30 & 17 \\
\hline The SI sessions have increased my interest in the subject & 18 & 27 & 22 & 24 & 9 \\
\hline By attending SI sessions I have improved my results in the course & 29 & 24 & 28 & 12 & 7 \\
\hline $\begin{array}{l}\text { The SI sessions have been an effective support to help me proceed in the } \\
\text { course }\end{array}$ & 21 & 20 & 32 & 16 & 11 \\
\hline
\end{tabular}

Have SI sessions had any influence on the students' studies and general skills? Answers to the related questions on the survey are given in table 7. Obviously the students don't seem to change their way of studying due to attending SI sessions. However, it seems that several general skills develop for a large portion of the attendees, especially the ability for teamwork and collaboration in groups, as well as the ability to present problems/solutions in front of others. This is also confirmed by the SI leaders. The SI leaders' responses to the related questions in their survey are given in table 8 . The SI leaders also believe that the students develop their problem solving skills. 
Table 7. Answers to questions put to attendees about the influence of SI sessions on the students' studies and general skills. Below the percentage (\%) of students is given for each alternative answer

\begin{tabular}{|c|c|c|c|c|c|}
\hline & 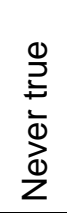 & 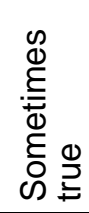 & 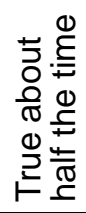 & 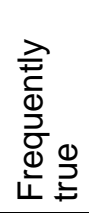 &  \\
\hline $\begin{array}{l}\text { The SI sessions have developed my way of studying. This will also be } \\
\text { useful in other courses. }\end{array}$ & 26 & 26 & 22 & 18 & 9 \\
\hline The SI sessions have developed my abilities in problem solving & 9 & 25 & 30 & 24 & 12 \\
\hline $\begin{array}{l}\text { The SI sessions have developed my ability in teamwork and collaboration } \\
\text { in a group }\end{array}$ & 11 & 16 & 22 & 33 & 19 \\
\hline $\begin{array}{l}\text { The SI sessions have developed my ability to critically review } \\
\text { material/questions/solutions in the course, by group discussions }\end{array}$ & 11 & 24 & 28 & 26 & 12 \\
\hline $\begin{array}{l}\text { The SI sessions have developed my ability to present problems/solutions } \\
\text { in the subject, in front of others }\end{array}$ & 19 & 12 & 22 & 30 & 18 \\
\hline $\begin{array}{l}\text { I have obtained better self confidence in my studies by attending SI } \\
\text { sessions }\end{array}$ & 20 & 23 & 30 & 16 & 11 \\
\hline
\end{tabular}

Table 8. Answers to questions put to SI leaders about the attending students' development of general skills. Below the percentage (\%) of SI leaders is given for each alternative answer

\begin{tabular}{|c|c|c|c|c|c|}
\hline & 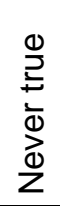 & 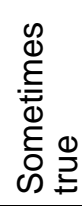 & 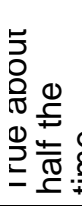 & 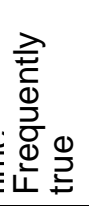 & 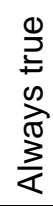 \\
\hline The SI sessions have developed the students' abilities in problem solving & 0 & 0 & 13 & 75 & 13 \\
\hline $\begin{array}{l}\text { The SI sessions have developed the students' abilities in team work and } \\
\text { collaboration in groups }\end{array}$ & 0 & 0 & 19 & 63 & 19 \\
\hline $\begin{array}{l}\text { The SI sessions have developed the students' abilities to present } \\
\text { problems/solutions in front of others }\end{array}$ & 0 & 19 & 19 & 44 & 19 \\
\hline $\begin{array}{l}\text { The SI sessions have developed the students' abilities to critically review } \\
\text { material/questions/solutions in the course, by group discussions }\end{array}$ & 0 & 6 & 50 & 38 & 6 \\
\hline
\end{tabular}

In order to get an idea of how the student's learning in a course/subject may change due to attending SI sessions, a special study at one upper secondary school was made. Here two parallel first year classes were compared with regard to learning in mathematics after one semester - one having SI and one not having SI. (The reason for choosing mathematics was that SI was just applied to this subject at this school). The classes had a similar gender distribution as well as distribution of math grades from the last year in intermediate school. It is therefore likely that their view on math studies, on average, were initially about the same in the two classes. The student responses to the questions in the survey are given in table 9. The student responses regarding learning in mathematics are quite similar in the two classes, with 


\section{Macrothink}

regard to the importance of working on your own and listening to a teacher's explanation, or discussing together in the entire class. This is to be expected, as these items are not developed at SI sessions. There is a statistically significant difference between the answers on one particular question. But pronounced differences exist in the average class answer on a number of questions about student learning in mathematics (and it is likely that these differences would be statistically significant with a relatively modest increase in group size). These are: solving problems on the white board in front of others, working in small groups, working with a class mate and explaining to a class mate, and are valued higher from a learning perspective by the class having attended SI sessions. Since these things are developed specifically at SI sessions, it would appear that the training has created changed attitudes with regard to learning math. Since the entire class did not participate in the SI sessions after the sessions became optional, the differences would probably have been more pronounced if one had specifically targeted the students who attended SI sessions regularly even after they became optional.

The fact that the students in the different upper secondary schools generally like to study the learning areas targeted in SI, is also shown by the answers to the open-ended question "What do you think is the best aspect of the SI sessions?". A couple of examples:

"The best thing is that you can understand how other people think and that you can use it."

"You get more explanations than just from the teacher, Different people have different views and may think in a different way than yourself. It is more fun than just going on solving problems."

Other illustrating examples - answers to the open-ended question " How do SI sessions differ from ordinary lessons?" are as follows:

"You can discuss problems in a group and thereafter present them in front of others. In lessons you normally just listen to the teacher."

"There are very few similarities. SI is almost just discussion and always group work, while lessons are the opposite."

"More discussions and the good feeling of being a part of a group. Everything is discussed and all students develop independent of how much they know." 


\section{MlMacrothink}

International Journal of Education

ISSN 1948-5476

2012, Vol. 4, No. 3

Table 9. Student answers to questions on how to learn mathematics in the best way. The answers are divided for the two classes - one that had SI in math (31 students) and one that did not have SI in math (29 students). The five answer alternatives have been converted into numbers where 1 equals never true and 5 equals always true, with the three other answers having numerical values in between. In the table the average values are given for each class for each question. Statistically significant differences using an independent t-test (two-sided distribution) with $\mathrm{p}<0.05$ compared to the group of students not attending supplemental instruction are marked with *

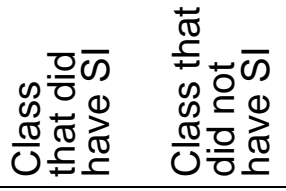

\section{I learn mathematics best by}

$\begin{array}{lll}\text { a) working on my own } & 4.3 & 4.2 \\ \text { b) working together with a classmate } & 3.9 & 3.4 \\ \text { c) explaining to a classmate } & 4.2 & 3.8 \\ \text { d) listening to the teacher explaining to the class } & 4.2 & 4.0 \\ \text { e) discussing a problem together with the whole class } & 3.2 & 3.2 \\ \text { f) working with problems in small groups } & 3.5 & 2.9 \\ \text { g) watching classmates solving problems on the whiteboard in front of the } & 3.2 & 2.9 \\ \text { class } & & \end{array}$

h) solving a problem on the whiteboard in front of the class

$3.3^{*} \quad 2.5^{\star}$

How do the university students feel that they have developed by being SI leaders in upper secondary school? All questions regarding improved personal skills have been answered affirmatively, see table 10. Self confidence, talking in front of others, organizing the work for a group, leading a discussion and leading a group, ability to meet and inspire individuals or group of individuals and getting students to help each other, are all areas where the SI leaders report that they have improved. This is also confirmed by the answers to open-ended questions, such as "List and explain three things that you have improved upon by being an SI leader":

"I have improved regarding listening and reflecting over things that come up in SI sessions. I'm more confident in myself, and how I should act in different groups and in situations that arise. It is also easier for me to talk in front of a group of people."

"Communication: to explain the same thing and give instructions in several different ways so that everyone really understands. Group dynamics and how groups work. Planning the SI session and identifying what students find difficult."

"I have become much better at distinguishing different personalities and moments in group work. I am much more secure in leading the work and have improved in providing challenging tasks." 
Thus it would appear that the SI leaders are big winners in the SI program in an upper secondary school.

Table 10. Answers to questions put to SI leaders about their personal development in being an SI leader. Below the percentage (\%) of SI leaders is given for each alternative answer

\begin{tabular}{|c|c|c|c|c|c|}
\hline & $\begin{array}{l}\stackrel{0}{\underline{D}} \\
\stackrel{ \pm}{\Phi} \\
\stackrel{\circlearrowright}{Z}\end{array}$ & 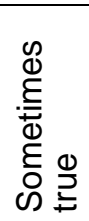 & 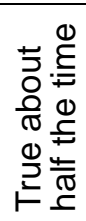 & 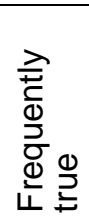 & 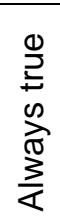 \\
\hline By being an SI leader I have improved my self confidence & 0 & 6 & 13 & 56 & 25 \\
\hline $\begin{array}{l}\text { By working as an SI leader I have improved my ability to talk in front of } \\
\text { others }\end{array}$ & 0 & 13 & 25 & 19 & 44 \\
\hline I have improved my ability to organize the work for a group & 0 & 6 & 0 & 50 & 44 \\
\hline I feel more secure in being a leader of a group & 0 & 6 & 13 & 25 & 56 \\
\hline I feel more secure in leading a discussion & 0 & 6 & 13 & 31 & 50 \\
\hline I have improved my ability to meet and inspire different individuals & 0 & 0 & 19 & 31 & 50 \\
\hline $\begin{array}{l}\text { I have developed my ability to enthuse a group of individuals to undertake } \\
\text { a task }\end{array}$ & 0 & 0 & 19 & 50 & 31 \\
\hline $\begin{array}{l}\text { I have become good at getting the students to help each other with the } \\
\text { course }\end{array}$ & 0 & 0 & 12 & 69 & 19 \\
\hline
\end{tabular}

\section{Discussion}

Above we have been able to conclude that SI seems to offer new dimensions in the learning of science subjects. What then do the students in upper secondary schools see as the differences between SI sessions and ordinary lessons? From a word count analysis on this open-ended question, a number of clearly marked differences appear, see table 11 . To discuss and talk with each other about the course/subject, and to work in groups, seem to be the clearest differences. It is also interesting to note that several students see the SI sessions as a source of pleasure. These differentiating activities are also valued by the students. To the open-ended question "What do you think is the best aspect of the SI sessions?" the most frequently used words in the answers are similar, see table 12. Thus we can conclude that many students feel that SI provides a different learning experience in the course and that this experience is something they appreciate.

Table 11. Most frequently used words (in 10 or more of a total of 120 answers) on the question "How do SI sessions differ from ordinary lessons?"

\begin{tabular}{lc}
\hline Word(s) & Occur in the following number of answers \\
\hline Discuss/talk to each other & 36 \\
Group & 29 \\
Pleasure/fun & 10 \\
\hline
\end{tabular}




\section{$\triangle$ Macrothink}

Table 12. Most frequently used words (in 10 or more of a total of 120 answers) on the question "What do you think is the best aspect of the SI sessions?"

\begin{tabular}{lc}
\hline Word(s) & Occur in the following number of answers \\
\hline Discuss/talk to each other & 33 \\
Pleasure/fun & 24 \\
Group & 22 \\
Solve problems & 14 \\
Understand & 12 \\
\hline
\end{tabular}

What then are the teachers' views on the SI sessions' contribution for their students? Some have difficulties in answering, as they had too much of a peripheral function in the SI collaboration. Some have not noticed any clear differences as far as they can tell. Others, being more involved in the SI cooperation, have noticed the clear influence of the SI sessions. Examples of such observations are evident in comments on the open-ended questions "Comment on how useful it has been for you to have SI sessions to complement your teaching" and "What do you see as the main influence that the SI sessions have had on your students?". Some examples:

"The students that regularly attend SI sessions during their time in upper secondary school have developed drastically, not just knowledge wise but also in their confidence in their own ability. I have also noticed that the students help each other more often. I see this as an effect of the SI sessions, where they see that explaining to a fellow student helps their own understanding."

"They see different kinds of questions and problems. They enjoy the sessions and find them helpful in their understanding. SI has also broadened their view on mathematics."

"They have learned how to work together"

"The SI leader provided them with a different point of view, which stimulated their curiosity and sense of enjoyment of the subject."

Thus it seems that SI sessions can work as a desirable complement to the regular educational activities. Furthermore SI can function, for instance, as a piece of the puzzle in developing communication in the subjects accentuated in the new Swedish curriculum for mathematics, in upper secondary school.

What then are the challenges in getting SI to work in upper secondary schools and as a link with university? There are several, but the most pronounced are

1) scheduling of SI sessions,

2) having good and involved contact people (teachers/principals) at the upper secondary school (and at university obviously), who have time to communicate with both students and SI leaders, and

3) ensuring that the students who are to attend the SI sessions, quickly get a good understanding of what SI is, since it differs from their regular education. 
Regarding the scheduling of SI sessions it is important that they are scheduled in the middle of the day, which can be hard to achieve. Too early or too late in the day will normally decrease attendance drastically. It is of the utmost importance that the contact person (normally the teacher responsible for the course) at the upper secondary school has a good grasp of the SI methodology and feels involved in the SI cooperation. Furthermore, the contact person has to have the support of the school leaders. This needs to be the case in order to get time to inform students about SI and urge them to attend SI sessions, and also make contact with SI leaders and the SI staff at the university. Otherwise it is likely that the students will not see the SI sessions as a valuable learning opportunity, but rather something on the side that is not deemed important by the school. It is also important that the students quickly get an understanding of the SI methodology, as this differs from the way they traditionally study the science subjects. As upper secondary school students are not as mature as university students, it is a good idea to make the SI sessions mandatory initially, so that the students get good firsthand experience of what SI is about in addition to the initial SI briefing information before the sessions start.

In the introduction, several potential advantages of the SI program for the upper secondary school were pointed out. For the upper secondary school student, there are actually more:

- Students understand the value of verbally communicating mathematics

- Students are more positive about showing their work to the class

- Students develop a higher self esteem concerning mathematics

The survey conducted by teachers at one upper secondary school, presented in table 9 above, shows that the students quite quickly realize the advantage of verbally communicating mathematics. The survey conducted in one class with SI meetings and one class without SI meetings, shows that students in receipt of SI seem more positive to working in small groups and explaining to a friend. These students seem to understand that it deepens the student's own understanding of mathematics while explaining to a friend. The new national curriculum of the upper secondary school lays emphasis on communication skills, and SI can be one way of realizing that target.

One benefit that takes a little longer to show is that students who attend SI meetings are more positive to solving problems on the whiteboard in front of the class and the teacher. In the survey this is the statement where the responses of students attending SI meetings differs the most from the ones not attending. At the SI meetings the students often have to explain a solution to a problem in front of the others. As they get used to this they get more relaxed when they show their work to the class. Attending SI meetings appears to strengthen the student's confidence and their will and drive to share their knowledge with others.

The benefit that takes longest to show is that students, who go to SI meetings during the whole time in upper secondary school, develop a deeper confidence concerning mathematics. This fact in conjunction with studying more and more mathematics causes the student to achieve better. This conclusion is based on an interview conducted by one teacher with a 
student who graduated in the year of 2011. The student attended every single SI meeting and progressed from being insecure concerning mathematics to becoming calm and steady and thereby producing better results.

\section{Conclusions}

The main conclusion is that the SI methodology also seems to work in an upper secondary school environment. Since the study is qualitative in nature we cannot claim that SI improves grades and results for the SI attending students in upper secondary school. However, the students who attend SI regularly appear to obtain new study strategies to increase their understanding of the subject, besides improving on general skills like teamwork, communicating with others on a subject, and making presentations in front of others. Thus it seems that SI, for these reasons alone, is worth exploring in an upper secondary school setting. Besides these potential advantages, there are several additional ones for the involved schools and university. In addition to gaining a formal and an informal link that can be useful in many circumstances when an exchange of information is needed, both can use SI as a means to boost recruitment. For the upper secondary school, the students can get an alternative view on subjects, which hopefully stimulates interest and understanding. The students also get a more mature role model to turn to. For the university they can provide the upper secondary school students with a more informal view of what it is like to study at university. However, the major beneficiaries of the SI program are most likely the SI leaders, who experience a distinct improvement in leadership ability and development in general skills, such as talking in front of others and inspiring and motivating individuals and groups.

\section{References}

Blanc, R.A., DeBuhr, L.E., \& Martin, D.C. (1983). Breaking the attrition cycle: The effects of Supplemental Instruction on Undergraduate Performance and Attrition. The Journal of Higher Education, 54 (1), 80-90.

Burmeister, S.L., Kenney, P.A., \& Nice, D.L. (1996). Analysis of Effectiveness of Supplemental Instruction (SI) Sessions for College Algebra, Calculus, and Statistics. CBMS Issues in Mathematics Education, 6, 146-154.

Congos, D.H., \& Schoeps, N. (1993). Does Supplemental Instruction really work and what is it anyway? Studies in Higher Education, 18(2), 165-176. http://dx.doi.org/10.1080/03075079312331382349

Hensen, K.A., \& Shelley, M.C. (2003). The Impact of Supplemental Instruction: Results from a Large, Public, Midwestern University. Journal of College Student Development, 44 (2), 250-259. http://dx.doi.org/10.1353/csd.2003.0015

Hurley, M., Jacobs, G., \& Gilbert, M. 2006. The Basic SI Model. In Supplemental instruction: New visions for Empowering Student Learning. New Directions for Teaching and Learning. No. 106., eds. M. E. Stone and Jacobs G., 11-22. Wiley Periodicals. 
Malm, J., Bryngfors, L., \& Mörner, L. (2011). Improving student success in difficult engineering education courses through Supplemental Instruction (SI) - what is the impact of the degree of SI attendance?, Journal of Peer Learning, 4(1), 16-23. Retrieved June 20, 2012 from http://ro.uow.edu.au/ajpl/vol4/iss1/4

Martin, D. 2008. Foreword. Australian Journal of Peer Learning, 1, 3-5. Retrieved June 20, 2012 from http://ro.uow.edu.au/ajpl/vol1/iss1/2

Ogden, P., Thompson, D., Russell, A., \& Simons, C. (2003). Supplemental Instruction: Short- and long-term impact. Journal of Developmental Education, 26(3), 2-8.

Packham, G., \& Miller, C. (2000). Peer-Assisted Student Support: a new approach to learning. Journal of Further and Higher Education, 24(1), 55-65. http://dx.doi.org/10.1080/030987700112318

Power, C., \& Dunphy, K. (2010). Peer Facilitated Learning in Mathematics for Engineering: a Case Study from an Australian University. Engineering education, 5(1), 75-84.

Ramirez, G. M. (1997). Supplemental Instruction: The long-term impact. Journal of Developmental Education, 21(1), 2-8.

Rye, P.D., Wallace, J., \& Bidgood, P. (1993). Instructions in learning skills: an integrated $\begin{array}{llll}\text { approach. Medical } & \text { Education, }\end{array}$ http://dx.doi.org/10.1111/j.1365-2923.1993.tb00305.x

Sawyer, S. J., Sylvestre, P. B., Girard, R. A., \& Snow, M. H. (1996). Effects of Supplemental Instruction on mean test scores and failure rates in medical school courses. Academic Medicine: Journal of the Association of American Medical Colleges, 71(12), 1357-1359. Retrieved June 20, 2012 from http://journals.lww.com/academicmedicine/Abstract/1996/12000/Effects_of_supplement al_instruction_on_mean_test.21.aspx

Webster, T., \& Hooper, L. (1998). Supplemental Instruction for introductory chemistry courses: A preliminary investigation. Journal of Chemical Education, 75(3), 328-331. Retrieved June 20, 2012 from http://www.jee.org/1998/october/567.pdf

Wright, G.L., Wright, R.R., \& Lamb, C. E. (2002). Developmental Mathematics Education and Supplemental Instruction: Pondering the Potential. Journal of Developmental Education,_26(1), 30-35.

\section{Copyright Disclaimer}

Copyright reserved by the author(s).

This article is an open-access article distributed under the terms and conditions of the Creative Commons Attribution license (http://creativecommons.org/licenses/by/3.0/). 